\title{
Strategic ICT Use for Social Innovation: A Case Study of "Irodori”
}

\author{
Tetsuji OGAWA ${ }^{\text {a) }}$, Hiroyasu YUHASHI ${ }^{\text {b) }}$, Masakatsu NISHIGAKI ${ }^{\text {a) }}$ \\ ${ }^{a}$ Graduate School of Science and Technology, Shizuoka University, \\ 3-5-1, johoku, naka, Hamamatsu, Shizuoka, 432-8011, Japan \\ ${ }^{b}$ Graduate School of Integrated Science and Technology, Shizuoka University, \\ 3-5-1, johoku, naka, Hamamatsu, Shizuoka, 432-8011, Japan
}

\begin{abstract}
As the key to success in a social business, creation of social innovation has been captured in collaboration with other organizations and entrepreneurships. This study acquires new insights on social innovation creation through a strategic perspective. The study selected a case of a successful social business and conducted framework analysis via the Blue Ocean Strategy and business process by the Design and Engineering Methodology for Organizations (DEMO). The study reveals that social innovation is created from the coexistence of creativity and productivity. Moreover, social business is necessary not only to avoid competitive markets and enter into undeveloped markets, but also to make efforts to differentiate and reduce costs.
\end{abstract}

\section{Keywords: Social Innovation, Blue Ocean Strategy, Business Process}

\section{Social Business}

A social business is one that incorporates various perspectives and innovative methods to address social problems [1]. Since various social problems, such as an aging population, unemployment, and depopulation, are becoming more prevalent in local societies, social businesses have attracted increasing attention as a concrete solution to such problems.

However, when social problems are handled as businesses, profitability generally decreases, and the business either fails or is not established in the first place. Therefore, it is necessary to create social innovation to balance business interests with social interests. In addition, since creation of social innovation is believed to be the key to success in social business, numerous studies have attempted to clarify determinants of social innovation-including discussions on human valuecreation networks that take place among various stakeholders involved in eradicating social problems [2] - and characteristics of social entrepreneurs [3]. Yet, since these nascent discussions have focused only on people-related aspects, determinants of social innovation have yet to be adequately clarified.

In addition, the number of social enterprises in Japan has increased in the recent years [4]. The number of nonprofit organizations (NPOs) has increased from 31,173 (2006) to 52,424 (2016). These are expected to increase further, especially by the inclusion of non-NPOs. This reflects an increase in social issues like Japan's aging and regional revitalization, and this trend is expected to continue in the future.
Therefore, even if a social enterprise enters a social business that attempts to resolve a specific social problem, competition may occur among social enterprises dealing with the same social issue and competing for market share [5]. When a social enterprise enters a social business, a strategic approach must be adopted. However, few studies have so far researched strategic approaches for social businesses. With this in mind, the present study addresses a case of a successful social business, analyzes it according to a strategic approach, and derives practical knowledge about the creation of social innovation.

\section{Framework of analysis}

\subsection{Literature Review}

So far, previous studies on social innovation have primarily focused on human value-creation networks (i.e., new business cooperation between various key figures) and characteristics of social entrepreneurs. In regard to the former, Phills et al. suggested that such networks are created by exchanging ideas and values among various stakeholders, such as those in government, private enterprises, and NPOs [6]. However, Mulgan et al. indicated that these networks are created by matching social entrepreneurs with social missions of government and civil society [2]. Tanimoto also referred to various community groups (e.g., social enterprises, intermediate support organizations, and universities that create social innovation) as social innovation clusters, which are created through cooperative relationships [8]. All of these studies agree that the source of social innovation is the connection among people. In regard to the latter, many

*Corresponding author: ogawa.tetsuji.15@shizuoka.ac.jp 
researchers have claimed that social entrepreneurial spirit is a multi-dimensional structure. Tanimoto treated social entrepreneurs as carriers of social innovation and explained that social innovation occurs when new business models are proposed and support from society becomes widespread [8]. In addition, Dees et al. indicated that social innovation is created according to the following behavioral characteristics of social entrepreneurs: the belief that solving social problems assumes priority over benefits, the desire to achieve social missions, the ability to conduct continuous learning processes, and the aim of acting without resources [3].

These studies have recognized that social innovation is created based on connection and interaction among people. However, although these studies have provided clues to create social innovation, the discussions have primarily focused on people-related aspects. As a result, their findings have low reproducibility, and discovering whether social innovation is created based on strategy is difficult. Therefore, grasping social business from a strategic viewpoint is necessary.

Next, in a study on enterprises' survival, Kotosaka declared it necessary to raise creativity and productivity to generate innovation that can survive the rapidly changing competitive environment [9]. Creativity creates markets based on new ideas and technologies thus building competitive advantage. Reducing production cost increases the productivity of businesses and services, introduction of information and communication technology (ICT) being one way of reducing production costs. As a method of creating innovation through coexistent creativity and productivity, creativity is generally left to experts (including external ones) and productivity shaves unnecessary organizational processes.

This study takes the perspective that companies in general need to nurture creativity and productivity to innovate and survive. However, others have observed that research scope has not reached social innovation that aims to solve social problems and that they cannot refer to concrete analytical methods.

On the basis of our literature review, the present study focuses on creativity and productivity to understand social innovation. Therefore, the research questions are as follows:

RQ 1: Is social innovation created from the coexistence of creativity and productivity?

RQ 2: Based on results of RQ1, is it possible to obtain new knowledge on social business?

Clarifying these questions can provide a foothold for organizing methods by which NPOs and social entrepreneurs can create social innovation using strategic approaches.

\subsection{Blue Ocean Strategy}

As one means to capture the creativity of social innovation, the blue ocean strategy avoids the existing market space and creates a previously undeveloped market space $[10,11]$. Blue ocean strategy does not attempt to overcome competitors within the existing industry's framework but increases the buyer's or company's value and develops a competitive market according to different strategic logic. Blue ocean also simultaneously pursues differentiation and low cost.

In contrast, red ocean strategy means competing for market share among other businesses to acquire greater demand in the existing markets.

Blue ocean strategy calls for a business to reduce, remove, increase, and add to succeed in the existing markets. Furthermore, in blue ocean strategy, "value innovation" is needed to lower costs and improve value for buyers. As a reason for using the framework of blue ocean strategy to analyze a social business's creativity, in some circumstances, a social business fights for market share among social enterprises and must therefore develop a market without competition.

\subsection{Business Process}

This study focuses on social businesses' process to grasp the productivity of social innovation. A business process is actually a series of processes to provide value to a business and can be visualized using a modeling method; thus, it is possible to obtain highly reproducible and practical suggestions. Any change in the business process will have a major effect on business innovation. Innovation occurs as a result of a change in the business process, especially a change caused by ICT [12].

This study was conducted to apply the DEMO model to compare business processes. The Business Process Model and Notation (BPMN) and Unified Modeling Language (UML) are two well-known models for business process modeling. Since both methods are based on a workflow perspective, expression of the entire business process becomes extremely detailed. As a result, it becomes difficult to grasp the overall picture from a bird's-eye view because aspects related to new creation and decision making get mixed. Thus, neither of these models is suitable for effectively comparing business processes [7].

In contrast, the DEMO model is based on an adjusted perspective, focusing on ontological aspects of activities involving human decision making [7]. In this sense, ontology is a deep structure hidden under observable surface layers and independent of implementation. In addition, since majority of the corporate activities are believed to be adjustments rather than acts of production, any changes in the business process can be modeled compactly. As a result, in contrast to the other models, this model makes it easier to compare business processes and examine/visualize any innovations that occur [7]. Ogawa et al. modeled business processes before and after ICT introduction of social business using DEMO in research on ICT and social innovation. Comparative 
analysis of the DEMO model showed four factors: 1) executor shift, 2) automation, 3) data sharing, and 4) acquisition of outside resources as the role of ICT in social business [13]. For these reasons, the DEMO model was selected for conducting this analysis.

\section{Methodology}

\subsection{Framework}

This study addresses a case of successful social innovation and analyzes its blue ocean strategy and DEMO business process. In an analysis based on the framework of blue ocean strategy, when social enterprises enter a social business, the study attempts to understand what strategy was used to generate creativity. DEMO modeling of business processes catches change in productivity while comparing models.

When describing the DEMO business process, information obtained from interviews of related persons and literature is used. By comprehensively studying these analysis results, our research questions are answered.

\subsection{Selection of Case}

According to Tanimoto's definition, a social business satisfies three requirements: social mission, business feasibility, and innovation [8]. Social mission means that the business's main aim is to alleviate a social problem. Business feasibility makes the social mission an ongoing enterprise. Finally, innovation means developing new social services and mechanisms to facilitate these services and creating new social value by spreading activities in the society.

This case study focuses on the Tsumamono business of the Irodori Corporation, which created social innovation by introducing the Point of Sales (POS) system and succeeded in social business. The reason for picking up this case is because its creativity pioneered the new Tsumamono market and its productivity introduced the POS system. In addition, it was possible to apply the blue ocean strategy and grasp changes in the business process before and after the introduction of the POS system in the DEMO model, thereby finding effective features for social innovation.

\subsection{Framework of the Blue Ocean Strategy}

Kim and Mauborgne developed a strategic canvas and an action matrix as frameworks to analyze blue ocean strategy [10]. A strategy canvas is a graph showing the market's competitive factors on its horizontal axis and customer value on its vertical axis, thus revealing the differences between existing and new businesses (Figure $1)$. $\underline{\text { High }}$

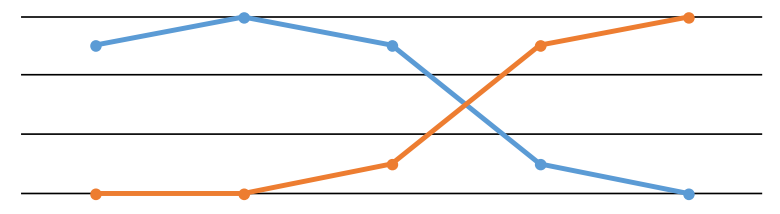

Low

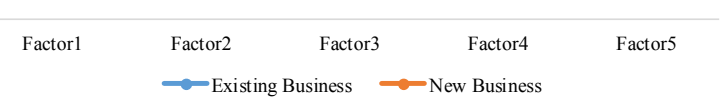

Figure 1. Example of a Strategy Canvas

An action matrix is an auxiliary tool for considering provision of new value to customers at four points: eliminate, reduce, raise, and create.

These analysis frameworks were derived from surveys of companies around the world. In particular, these two form the central framework for analyzing blue ocean strategy. Therefore, this study uses the strategic canvas and the action matrix.

\subsection{Description of the DEMO Model}

In the DEMO model, the act of creating a product is regarded as a unit, the group of actions is called a transaction, and a participant is referred to as the actor role. In Figure 2, the rectangle represents the actor role, which is either an initiator or an executor, and the rhombus in a circle represents a transaction, which is a group of production or adjustment acts. The actor role marked with the rhombus represents the executor of the transaction, whereas the rhombus in the gray circle represents the necessary data for transaction execution, also called the transaction bank. In addition, the dashed line is called the information link that indicates the transaction bank.

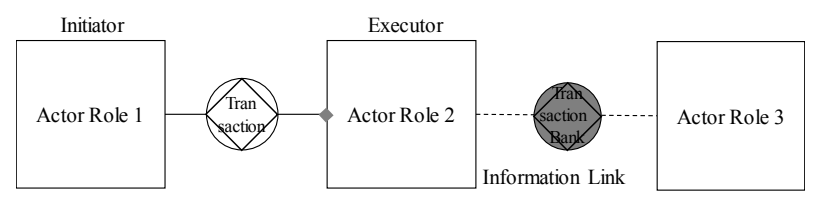

Figure 2. Example of the DEMO Model

\subsection{Interview Survey}

An interview survey was conducted for two reasons. First, it could provide an understanding of competitive factors in the Tsumamono market. Second, while the DEMO model analyzed the business process at an ontological level with key figures, the interview could help to better understand their decision-making activities. In addition to face-to-face interviews, subjects were interviewed by e-mail or over telephone several times to grasp details in multiple ways. Main interview items were aligned with research questions and interview results

Vol. 9 No.1 (2017) 
were audio recorded (by digital voice recorder) and subsequently documented in writing.

\section{Case Analysis of Irodori}

\subsection{Case Study}

The Tsumamono business of Irodori is a social business in Kamikatsu town (Tokushima Prefecture), Japan. Kamikatsu town is located $40 \mathrm{~km}$ from the city of Tokushima, and is surrounded by the high Shikoku Mountain Range, mostly forested, except for a few flat areas. Currently, the town's population is 1,662 , with an aging rate of $51.93 \%$ (April 1, 2016). This town has the smallest population in Shikoku, along with the highest aging rate in Tokushima Prefecture.

As the main industry, mandarin orange production had been very active but, in 1981, the orange trees withered in a cold spell of minus 13 degrees. Farmers who had been raising oranges for many years received a great shock, many lost their something to live for, and the atmosphere of the town became very dark. Kamikatsu's social problem then was to develop local industries instead of raising oranges and to provide something to live for farmers. To solve these social problems, Shoji Yokoishi, an official of Japanese Agriculture (JA) East Tokushima at the time, initiated the Tsumamono business in 1986.

Specifically, the Tsumamono business commercializes and ships leaves, such as maple, persimmon, and nandina, to decorate food. Kamikatsu town lies at high altitude, and its seasonal change is fast, so farmers can harvest the anticipated leaves. Furthermore, the harvest can be lengthened because of the difference in the town's altitude [14].

In this case, a social mission created a local industry and something to live for former orange farmers. Business feasibility was established with annual sales of 260 million yen (2015). Furthermore, since Tsumamono created business innovations that function well by introducing the POS system utilizing ICT, the Tsumamono business can therefore be regarded as a social business, and its innovation can be called social innovation.

\subsection{Analysis using Blue Ocean Strategy}

To get the Tsumamono, a chef had to buy some local JA or found it on the mountain himself.

To grasp the Tsumamono market, nine business competition factors were defined: quality, stable supply, type, brand, size, delivery, channel, price, and freshness. Through interviews, a strategy canvas with the Irodori Corporation and local JA (Figure 3 ) is created. By scoring and plotting for each factor and then connecting the points, the value curve obtained reveals the Tsumamono market's characteristics. That is, the strategy canvas shows that all scores for Irodori are high, except for freshness. Freshness is high for local JA because the leaves are locally grown and locally consumed. In contrast, Irodori ships leaves to Tokyo, Osaka, Kyushu, and so on, so they arrive at restaurants the next day.

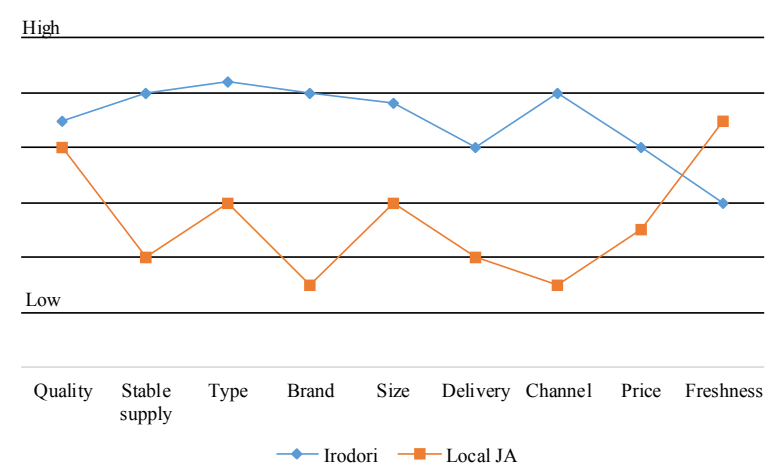

Figure 3. Strategy Canvas of Irodori

Figure 4 shows Irodori's action matrix. For eliminate, the existing production system of oranges was removed. Irodori introduced the POS system and analyzed data collected from the market to determine the production volume that maximizes profit. Furthermore, the production system created challenges by acquiring orders. For reduce, the effect of JA East Tokushima was decreased. Irodori is independent from JA East Tokushima as a third-sector information consulting company that analyzes market data and calculates appropriate production volume. For raise, there were the following aspects: type, stable supply, unification of sizes, and delivery speed. Finally, for create, there were actions like developing a new market for Tsumamono, improving farmers' motivation, and introducing marketing and branding.

\begin{tabular}{|l|l|}
\hline Eliminate & Raise \\
$\cdot$ Old Production System & $\begin{array}{l}\cdot \text { Type } \\
\cdot \text { Stable Supply } \\
\cdot \text { - Delivery Speed }\end{array}$ \\
\hline Reduce & $\begin{array}{l}\text { Create } \\
\cdot \text { Development of Tsumamono } \\
\text { market } \\
\cdot \text { Introduction of the Marketing } \\
\cdot \text { Branding }\end{array}$ \\
\hline
\end{tabular}

Figure 4. Action Matrix of Irodori

\subsection{Analysis by DEMO}

In 1999, Irodori was established as the third sector of Kamikatsu town to expand Tsumamono's sales. Introducing the POS system, Yokoishi became the CEO for Irodori Corporation, which is an information consulting company that analyzes and provides Tsumamono's demand and market information to farmers. The Irodori business model receives a part of sales from farmers as a fee. The POS system is called the "Irodori information network" that connects farmers, JA East Tokushima, and Irodori via a network and provides ordering support functions. By introducing the POS 
system, productivity was improved through an adjusted business process. Figure 5 shows Tsumamono's business processes according to the DEMO model before the introduction of the POS system. In the DEMO model, there were the following: market; individuals in charge of shipping, orders, and ordering to farmers; and farmers in actor roles.

At that time, the market requested a market order processing transaction to individuals in charge of orders. That individuals then requested an order processing transaction to the individuals in charge of ordering to farmers. Based on order processing, the individuals executed ordering to farmers - order request contact by telephone, one by one. If the farmer responded to the order, the individuals in charge of ordering to farmers confirmed the transaction; the individuals then requested an order processing transaction to individuals in charge of orders. The farmer executed a JA shipment transaction to the individuals in charge of shipping. Finally, the individuals in charge of shipping, who collected Tsumamono from each farmer, executes a shipment transaction to the market.

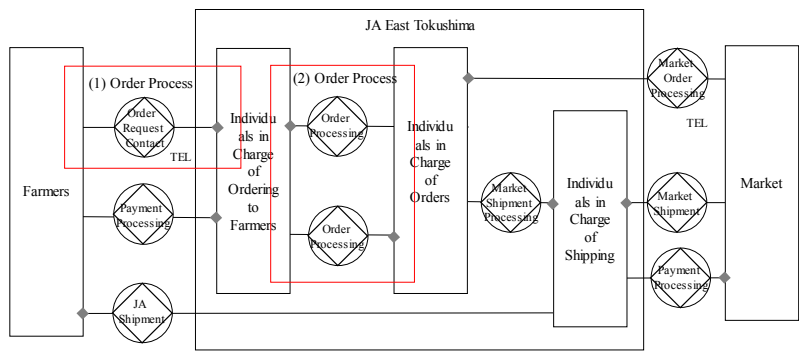

Figure 5. DEMO before Introduction of POS System

Next, Figure 6 shows the DEMO business process after the introduction of the POS system, wherein the business process contains a market, Irodori, JA East Tokushima, and farmers in actor roles. All orders from the market go through JA East Tokushima. When an order processing transaction is requested from the market to JA East Tokushima, the order is shared with Irodori through the POS system.

Market information and sales results provided by the market are also gathered at Irodori through the POS system. Irodori analyzes data and information collected from the market and discloses to farmers the target number of shipments. When the farmer receives an order transaction for Irodori with the disclosed target number of shipments, the order is confirmed. The POS system is described as a transaction bank, and it connects JA East Tokushima, Irodori, farmers, and markets along a broken line. When the farmer executes the JA shipment transaction to JA East Tokushima, JA East Tokushima executes the market shipment transaction to the market.

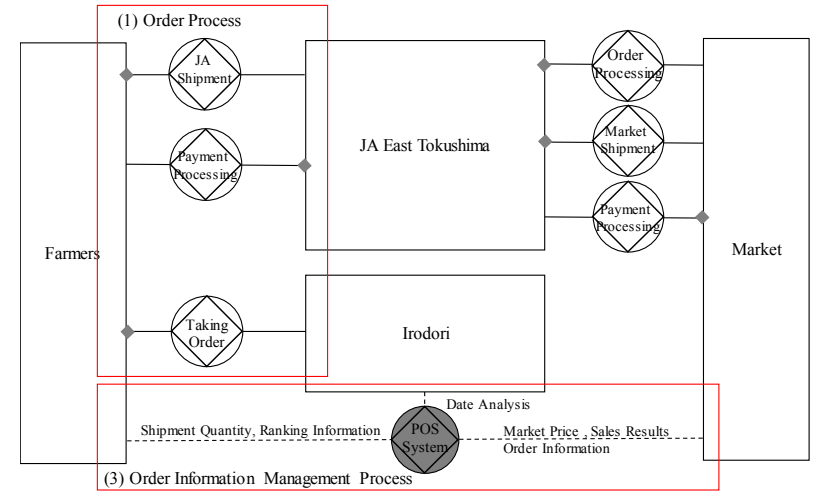

Figure 6. DEMO after Introduction of POS System

\section{Discussion}

\subsection{Creation of Creativity}

According to the strategic canvas's value curve (Figure 3), Irodori has higher values than local JA, except for freshness. This shows that Irodori has developed the new market with high-quality Tsumamono. Moreover, from the action matrix (Figure 4), Irodori has created new value with introduction of marketing and branding. This shows that not only is there new development in the Tsumamono market but also various values have been created through the POS system's introduction. This is how Irodori is implementing the blue ocean strategy, which is generating creativity.

\subsection{Improving Productivity}

Comparison of Figures 6 and 7 shows that the DEMO model has changed greatly; this means that the business process is changing. After the introduction of the POS system, farmers, JA East Tokushima, and Irodori, connected through the information link, are now networked and can access the POS system as a transaction bank. In the order process (1) between JA East Tokushima and farmers, before the introduction of the POS system, JA East Tokushima made contact to execute transactions of order requests. In contrast, after introduction of the POS system, there only remains the receipt of the order transaction and the farmers taking order execution of the transaction. In other words, part of the order process has shifted due to the POS system from JA East Tokushima to farmers, thus reducing JA East Tokushima's operations.

Next, in order process (2) in JA East Tokushima, prior to the POS system, an order processing transaction was executed by individuals in charge of orders and individuals in charge of ordering to farmers. In contrast, after the introduction of the POS system, JA East Tokushima conducts no transactions of order processing, thus indicating that the POS system has automated order processing. In other words, the POS system has reduced JA East Tokushima operations. 
Finally, in the order information management process (3), an information link connects farmers, JA East Tokushima, and Irodori. The Tsumamono business needs to control the market supply to maximize profit. As a mechanism to realize this, the POS system shares market trends, shipping targets, etc. in real time, thus enabling an environment for accessing that information from anywhere. In other words, the POS system performs data sharing, and makes it possible for farmers to judge the quantity of supply to maximize profit. Therefore, the POS system has improved productivity, reduced operations, and maximized profit.

\section{Conclusion}

Although numerous studies have focused on social innovation, they primarily examined interactions between people and organizations and characteristics of social entrepreneurs. Therefore, contributing to our knowledge base, the present study proposes that social innovation is generated from the coexistence of creativity and productivity. Therefore, this study's significance includes the following two points.

First, social innovation is generated not only from human interaction and characteristics of social entrepreneurs but also from the coexistence of creativity and productivity. Clearly, in addition, the analytical framework of the blue ocean strategy and the DEMO business process are effective. Findings show this framework as a new approach to the social innovation creation process.

Second, in social business, avoiding competitive markets and entering undeveloped markets is effective. Even so, making efforts to differentiate and lower costs for a social business's success is necessary. Irodori has created social innovation by developing a new Tsumamono market and improving of its productivity. However, Irodori is also improving the quality of social business by creating value, i.e., expanding types, maintaining a stable supply, introducing marketing and branding, and so on. Irodori occupies approximately $80 \%$ of the market share of Tsumamono and this shows that even after developing a new market, the company has continued efforts to differentiate and lower its costs so that latecomers do not deprive it of its share.

Finally, this study clarified that merging creativity with productivity can generate social innovation. In addition, to make a social business successful after generating social innovation, differentiation and cost reduction efforts must continue. However, since this study focused on a single case of social business and is only a hypothesis, future studies should expand such research into other contexts to deepen our understanding of generating social innovation and prove the effectiveness of this methodology.

\section{References}

[1] Ministry of Economy, Trade and Industry: Social Business Kenkyuukai Houkokusyo (in Japanese), Ministry of Economy, Trade and Industry, (2008), (accessed January 15, 2017), [available at http://www.meti.go.jp/policy/local_economy/sbcb/sbken kyukai/sbkenkyukaihoukokusho.pdf].

[2] G. Mulgan, S. Tucker, A. Rushanara and B. Sa nders: Social Innovation. What it is, Why it Matters and How it can be Accelerated (The Young Founda tion, 2007), (accessed February 10, 2017), [available at https://youngfoundation.org/wp-content/uploads/201 2/10/Social-Innovation-what-it-is-why-it-matters-how-it -can-be-accelerated-March-2007.pdf].

[3] J. G. Dees, J. Emerson and P. Economy: Enterprising Nonprofit: A Toolkit for Social Enterpreneurs (John Wiley \& Sons INC, 2001).

[4] The Cabinet Office: Changes in the number of certified NPOs (in Japanese), (The Cabinet Office, 2017), (accessed February 20, 2017), [available at https://www.npo-homepage.go.jp/about/toukei-info/nins hou-seni].

[5] Japan Finance Corporation: Social Business /Community Business ni kansuru annkerto no kekka nitsuite (in Japanese) (Japan Finance Corporation, 2014), 5-41, (accessed February 22, 2017), [available at https://www.jfc.go.jp/n/findings/pdf/sme_findings 14091 2.pdf].

[6] J. A. Phills, K. Deiglemeier and D. T. Miller: Rediscovering Social Innovation (Stanford Social Innovation Review, 2008), 34-43.

[7] J. Iijima: DEMO (in Japanese) (NTT Publishing Co., Ltd, 2014), 5-41.

[8] K. Tanimoto: Social Enterprise (in Japanese), (Chuokeizai Publishing Co., Ltd., 2006), 1-45.

[9] M. Kotosaka: How Creativity Productivity Can Mutually Coexist in a Company (in Japanese), (Diamond Harvard Business Review ,2014), 38-51.

[10] W. C. Kim and R. A. Mauborgne: Blue Ocean Strategy. (Harvard Business Review, 2004), 70-79.

[11] W. C. Kim, and R. A. Mauborgne: Blue Ocean Strategy: How to Create Uncontested Market Space and Make the Competition Irrelevant (Harvard Business School Press, 2005).

[12] Davenport, T. H.: Process Innovation: Reengineering Work through Information Technology, (Boston, MA: Harvard Business School Press, 1992).

[13] T. Ogawa, H. Yuhashi and M. Nishigaki: Roles of ICT in Social Innovation: A Comparative Study for Social innovation Based on Business Process Perspective (in Japanese), (Journal of the Japan Society for Management Information Vol.25 No.4, March 2017), 271-292.

[14] T. Yokoishi: Souda Happa wo Urou (in Japanese), (SoftBank Creative Publishing Co., Ltd., 2007), 138-156. 